\title{
Variability of subsequent blood pressure measurements carried out among adult volunteers
}

\author{
Martyna Schönborn', Agnieszka Trynkiewicz', Małgorzata Cebeńko', Danuta Czarnecka², \\ Agnieszka Olszanecka² \\ 'Students' Scientific Group at the $1^{\text {st }}$ Department of Cardiology, Interventional Electrocardiology and Hypertension, \\ Jagiellonian University Medical College, Krakow, Poland \\ ${ }^{2}{ }^{\text {st }}$ Department of Cardiology, Interventional Electrocardiology and Hypertension, Jagiellonian University Medical College, Krakow, Poland
}

\begin{abstract}
Background. Arterial hypertension (AH) affects 31\% of Polish adult population. However, proper evaluation of blood pressure (BP) is compromised by the phenomenon of its variability. The purpose of the study was to assess the variability of subsequent $\mathrm{BP}$ measurements and to define its determining factors.

Material and methods. Data were collected among volunteers during World Hypertension Day 2017 in Kraków. Information about socio-demographic status, cardiovascular risk factors and concomitant diseases were obtained with use of standardized questionnaires. Systolic blood pressure (SBP), diastolic blood pressure (DBP) and heart rate were measured thrice. The differences between consecutive measurements were analysed.

Results. The study included 419 participants (age $48.7 \pm 19.6$ years; $56.1 \%$ females). The first SBP and DBP measurements were significantly higher than the second and the third one.

In multiple regression analysis - age, first BP value and sex were significantly related with BP variability. Elevated $\mathrm{BP}$ among subjects without previous history of $\mathrm{AH}$ was detected in 119 participants (diagnosis based on the $1^{\text {st }} \mathrm{BP}$ reading) and in 79 when diagnosis was based on the average of the $2^{\text {nd }}$ and $3^{\text {rd }}$ measurements.

Conclusions. Consecutive BP measurements are highly variable. These differences are gender-related and the extend of $\mathrm{BP}$ decline is determined significantly by the first $\mathrm{BP}$ value. Correct measurement and interpretation of the $\mathrm{BP}$ is essential in the diagnosis and management of $\mathrm{AH}$. The combination of the $2^{\text {nd }}$ and $3^{\text {rd }}$ reading seems to be favourable over single reading; therefore, multiple BP measurements should be recommended even in screening actions. Key words: arterial hypertension; blood pressure measurement; blood pressure variability

Arterial Hypertens. 2019, vol. 23, no. 1, pages: 22-29

DOI: 10.5603/AH.a2018.0021
\end{abstract}

\section{Introduction}

Arterial hypertension $(\mathrm{AH})$ is one of the main risk factors of cardiovascular diseases and one of the most important health and social problems [1]. Of- fice blood pressure (BP) remains in strong and direct linear relationship with the prevalence of cardiovascular events such as myocardial infarction, stroke, sudden death and heart failure [2]. In Poland the

Address for correspondence: Agnieszka Olszanecka
$1^{\text {st }}$ Department of Cardiology, Interventional Electrocardiology and Hypertension, Jagiellonian University Medical College,
Kopernika 17, 31-501 Kraków, tel: +48 1242473 00, e-mail: agnieszka.olszanecka@uj.edu.pl

V M Copyright (C) 2019 Via Medica, ISSN 2449-6170 
prevalence of $\mathrm{AH}$ is estimated at around $32 \%$ of adults. Based on the results of the NATPOL 2011 and PolSenior trials, it can be estimated that the number of adults aged 18-79 years with $\mathrm{AH}$ in Poland is around 9.8 million, while the number of hypertensives over 80 years is around 1 million [3]. Hypertension is predominantly an asymptomatic condition that is best detected by structured population screening programmes or opportunistic measurement of BP. When structured population screening programmes have been undertaken, an alarming number of subjects $(>50 \%)$ were unaware they had hypertension. According to 2018 ESH/ ESC guidelines for the management of arterial hypertension, $\mathrm{AH}$ is defined as systolic blood pressure $(\mathrm{SBP}) \geq 140 \mathrm{~mm} \mathrm{Hg}$ and/or diastolic blood pressure $(\mathrm{DBP}) \geq 90 \mathrm{~mm} \mathrm{Hg}$ during repeated office BP measurements. Nevertheless, the diagnosis of $\mathrm{AH}$ may be also confirmed using ambulatory blood pressure monitoring (ABPM) or home blood pressure measurements (HBPM) [4]. As arterial pressure undergoes precise regulations by neural and hormonal influences with detectable beat-to-beat differences, the phenomenon of its variability is inexorable and relentless. As a result, BP measurements obtained from subsequent readings may be highly variable. The phenomenon of BP variability can be observed during the usual procedure of subsequent BP evaluations. It is strongly connected with the alert reaction to the doctor's visit or procedure of BP measurement itself [5]. Considering the important clinical and epidemiological implications of variations in measured BP, it should be underlined that described phenomenon could lead to variable diagnosis and bias in BP estimates and hypertension frequencies from epidemiological studies. Schulze at al. showed that the number of BP readings determines hypertension prevalence estimates [6].

The purpose of our study was to assess the extent of blood pressure variability in the subsequent measurements performed during screening action and to define its determining factors.

\section{Material and methods}

Data were collected among 419 volunteers during World Hypertension Day 2017 - a campaign promoting knowledge about arterial hypertension in the general population. The main inclusion criterion was the age equal or above 18 . There were no specific exclusion criteria. An informed voluntary consent to take part in the study was given by all of the participants.
The socio-demographic information was collected by face-to-face interviews using standardized questionnaires. The questionnaire comprised 14 closedand open-ended questions. The first part contained information about age, sex, ethnicity, use of antihypertensive drugs, presence of pregnancy, history of diabetes and myocardial infarction or stroke in the past. The second part referred to frequency of alcohol consumption (never or rarely, less than once a week and regularly), cigarette smoking as well as information about height and body mass. Body mass index (BMI) was calculated as body weight in kilograms divided by the square of body height in meters (values declared by participants). The overweight was defined as BMI $\geq 25$ and $<30 \mathrm{~kg} / \mathrm{m}^{2}$ and obesity as $\mathrm{BMI} \geq 30 \mathrm{~kg} / \mathrm{m}^{2}$.

Measurements of SBP, DBP and heart rate were performed after collecting the questionnaire. All readings were measured in the sitting position, following standards of BP measurements. BP was measured in both arms and repeated twice on the arm on which first BP value was higher with 1-2 minute intervals between. All measurements were performed with the use of validated automated oscillometric monitor [Microlife BP A6 PC (BP3GU1-8Y)]. Mean SBP and DBP were calculated using three consecutive measurements. Elevated BP was defined as SBP $\geq 140 \mathrm{~mm} \mathrm{Hg}$ and/or DBP $\geq 90 \mathrm{~mm} \mathrm{Hg}$ in any one of the three readings.

\section{Statistical analysis}

Data management and statistical analysis was performed with the use of Statistica 12.0 software (StatSoft, Statistica 12.0, Tulsa, Oklahoma, USA). Qualitative data were presented as values and percentages and quantitative data as values with the standard deviation. The Spearman's correlation and Student's t-test were used to evaluate the comparisons of quantitative data. For all tests, the $\mathrm{p}$ value $<0.05$ was considered statistically significant. Multiple regression models were performed in order to determine the predictor variables that were statistically significant.

\section{Results}

The study group included 419 participants, 235 women $(56.1 \%)$ and 184 men $(43.9 \%)$. The mean age of subjects included in the study was $48.7 \pm$ 19.6 years. The average BMI of the study group was $2.1 \pm 4.5 \mathrm{~kg} / \mathrm{m}^{2}$. One hundred thirty participants $(31 \%)$ were overweight and $53(12.6 \%)$ were obese. The use of antihypertensive drugs was reported by 
$124(29.6 \%)$ and diagnosed diabetes mellitus by 26 $(6.2 \%)$ volunteers. The past history of myocardial infarction was present in $12(2.9 \%)$ subjects and stoke in $6(1.4 \%)$. There were $55(13.1 \%)$ current smokers in the population under the study.

Seventy-two participants (17.2\%) reported consuming alcohol regularly, while $183(43.7 \%)$ consumed alcohol less than once a week and 153 $(36.5 \%)$ never or rarely.

Differences in BP and HR values between males and females and differences dependent on the antihypertensive medication use, cigarette smoking, al- cohol consumption and other factors are presented in Table I. Higher BP values were observed in males, subjects using antihypertensive medications, individuals with overweight or obesity and those reporting regular alcohol consumption.

Mean SBP values were positively correlated with the age of the participants (Fig. 1). Similarly, mean SBP and DBP correlated with BMI level (Fig. 2).

Values of SBP, DBP and HR in consecutive measurements are presented in Figure 3. SBP and DBP values decreased significantly from the first to the third reading. The first SBP measurement was sig-

Table I. The socio-demographic data and the values of SBP, DBP and HR (data are presented as means \pm standard deviation)

\begin{tabular}{|c|c|c|c|}
\hline & \multicolumn{2}{|c|}{ Gender } & \multirow{2}{*}{$\mathbf{p}$} \\
\hline & Women $(n=235)$ & Men $(n=184)$ & \\
\hline $\mathrm{SBP}^{1}$ & $127.3 \pm 19.5$ & $139.1 \pm 16.6$ & $<0.00001$ \\
\hline $\mathrm{DBP}^{1}$ & $77.2 \pm 9.3$ & $81.8 \pm 11.4$ & $<0.01$ \\
\hline \multirow[t]{3}{*}{$H R^{1}$} & $78.3 \pm 12.1$ & $76.7 \pm 12.7$ & 0.18 \\
\hline & \multicolumn{2}{|c|}{ Antihypertensive drug use } & \multirow{2}{*}{$\mathbf{p}$} \\
\hline & Yes $(n=124)$ & No $(n=295)$ & \\
\hline SBP & $142.3 \pm 20.4$ & $128.4 \pm 17.0$ & $<0.001$ \\
\hline $\mathrm{DBP}$ & $81.3 \pm 10.9$ & $78.3 \pm 10.3$ & 0.01 \\
\hline \multirow[t]{3}{*}{$H R$} & $73.2 \pm 10.5$ & $79.4 \pm 12.7$ & 0.001 \\
\hline & \multicolumn{2}{|c|}{ Diabetes mellitus } & \multirow{2}{*}{$\mathbf{p}$} \\
\hline & Yes $(n=26)$ & No $(n=393)$ & \\
\hline SBP & $136.8 \pm 17.0$ & $132.2 \pm 19.3$ & 0.24 \\
\hline $\mathrm{DBP}$ & $75.6 \pm 10.1$ & $79.4 \pm 10.5$ & 0.07 \\
\hline \multirow[t]{3}{*}{$\mathrm{HR}$} & $76.5 \pm 12.4$ & $77.6 \pm 11.8$ & 0.67 \\
\hline & \multicolumn{2}{|c|}{ Cigarette smoking } & \multirow{2}{*}{$\mathbf{p}$} \\
\hline & Yes $(n=55)$ & No $(n=364)$ & \\
\hline SBP & $132.2 \pm 18.7$ & $132.5 \pm 19.2$ & 0.89 \\
\hline $\mathrm{DBP}$ & $78.6 \pm 10.4$ & $79.3 \pm 10.6$ & 0.68 \\
\hline \multirow[t]{3}{*}{$\mathrm{HR}$} & $82.9 \pm 14.3$ & $76.8 \pm 11.9$ & $<0.001$ \\
\hline & & & \multirow{2}{*}{$\mathbf{p}$} \\
\hline & Yes $(n=53)$ & No $(n=366)$ & \\
\hline SBP & $143.3 \pm 17.7$ & $130.7 \pm 18.8$ & $<0.001$ \\
\hline $\mathrm{DBP}$ & $82.4 \pm 12.4$ & $78.6 \pm 10.1$ & 0.01 \\
\hline \multirow[t]{3}{*}{$H R$} & $79.7 \pm 12.6$ & $77.0 \pm 11.2$ & 0.14 \\
\hline & & & \multirow{2}{*}{$\mathbf{p}$} \\
\hline & Yes $(n=130)$ & No $(n=289)$ & \\
\hline SBP & $136.9 \pm 18.5$ & $130.2 \pm 19.5$ & $<0.001$ \\
\hline $\mathrm{DBP}$ & $77.6 \pm 10.0$ & $82.2 \pm 10.8$ & $<0.001$ \\
\hline \multirow[t]{3}{*}{ HR } & $78.8 \pm 10.1$ & $78.2 \pm 10.8$ & 0.59 \\
\hline & & & \multirow{2}{*}{$\mathbf{p}$} \\
\hline & Never or rarely $(n=183$ ) & Less than once a week $(n=153)$ & \\
\hline SBP & $134.1 \pm 20.8$ & $128.9 \pm 17.3$ & 0.02 \\
\hline
\end{tabular}


Table I. The socio-demographic data and the values of SBP, DBP and HR (data are presented as means \pm standard deviation)

\begin{tabular}{|c|c|c|c|}
\hline & \multicolumn{2}{|c|}{ Alcohol consumption } & \multirow{2}{*}{$\mathbf{p}$} \\
\hline & Never or rarely $(n=183)$ & Regularly (n = 72) & \\
\hline \multirow[t]{3}{*}{ DBP } & $78.8 \pm 10.1$ & $81.9 \pm 10.3$ & 0.02 \\
\hline & \multicolumn{2}{|c|}{ Alcohol consumption } & \multirow{2}{*}{$\mathbf{p}$} \\
\hline & Less than once a week ( $n=153$ ) & Regularly (n = 72) & \\
\hline SBP & $128.9 \pm 17.3$ & $136.1 \pm 18.1$ & $<0.01$ \\
\hline \multirow[t]{3}{*}{ DBP } & $78.2 \pm 10.8$ & $81.9 \pm 10.3$ & 0.03 \\
\hline & \multicolumn{2}{|c|}{ Myocardial infarction in the past } & \multirow{2}{*}{$\mathbf{p}$} \\
\hline & Yes $(n=12)$ & No $(n=407)$ & \\
\hline SBP & $137.1 \pm 14.8$ & $132.3 \pm 19.3$ & 0.39 \\
\hline $\mathrm{DBP}$ & $76.2 \pm 8.5$ & $79.2 \pm 10.5$ & 0.34 \\
\hline \multirow[t]{3}{*}{$\mathrm{HR}$} & $76.0 \pm 12.2$ & $77.5 \pm 14.7$ & 0.68 \\
\hline & \multicolumn{2}{|c|}{ Stroke in the past } & \multirow{2}{*}{$\mathbf{p}$} \\
\hline & Yes $(n=6)$ & No $(n=413)$ & \\
\hline SBP & $137.1 \pm 11.7$ & $132.4 \pm 19.3$ & 0.55 \\
\hline DBP & $75.5 \pm 7.4$ & $79.1 \pm 10.5$ & 0.39 \\
\hline $\mathrm{HR}$ & $77.4 \pm 9.9$ & $77.5 \pm 12.3$ & 0.99 \\
\hline
\end{tabular}

'The average value of three consecutive measurements; SBP — systolic blood pressure (mm Hg); DBP — diastolic blood pressure $(\mathrm{mm} \mathrm{Hg})$; $\mathrm{HR}$ — heart rate (beats/min)

nificantly higher than the second one $(136.4 \pm 20.0$ vs. $13.1 \pm 21.0 ; \mathrm{p}<0.00001)$ and the third one $(136.4 \pm 20.0$ vs. $129.9 \pm 1.3 ; \mathrm{p}<0.00001)$ with the largest decline from the first to the second. The first
DBP was also significantly higher than the second one $(81.1 \pm 11.3 v$ s. $78.8 \pm 10.9 ; \mathrm{p}<0.0001)$ and the third one $(8.1 \pm 11.3$ vs. $78.1 \pm 11.0 ; \mathrm{p}<0.0001)$. $\mathrm{BP}$ declines were more marked for SBP than for

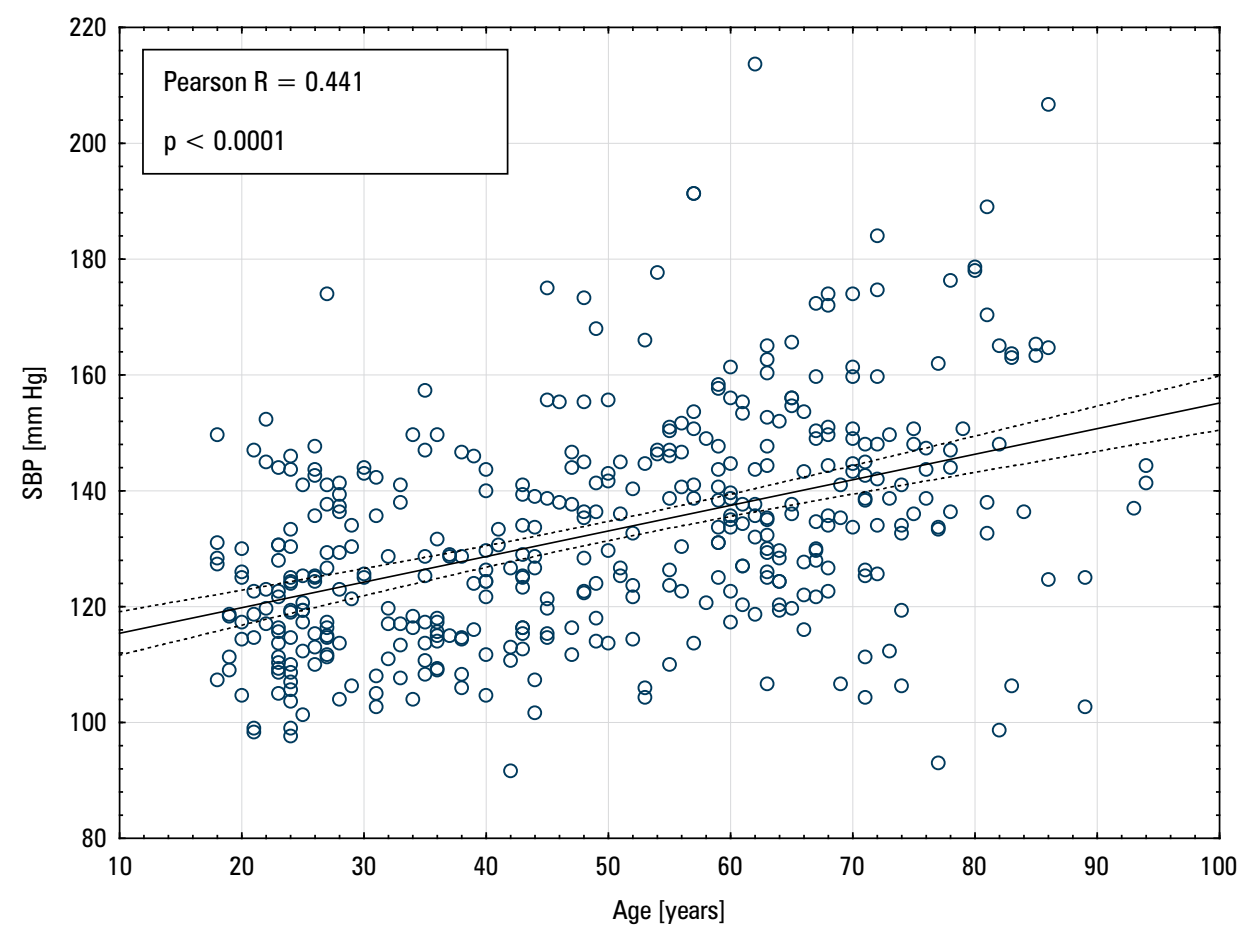

Figure 1. Correlation between mean systolic blood pressure (SBP) and age 

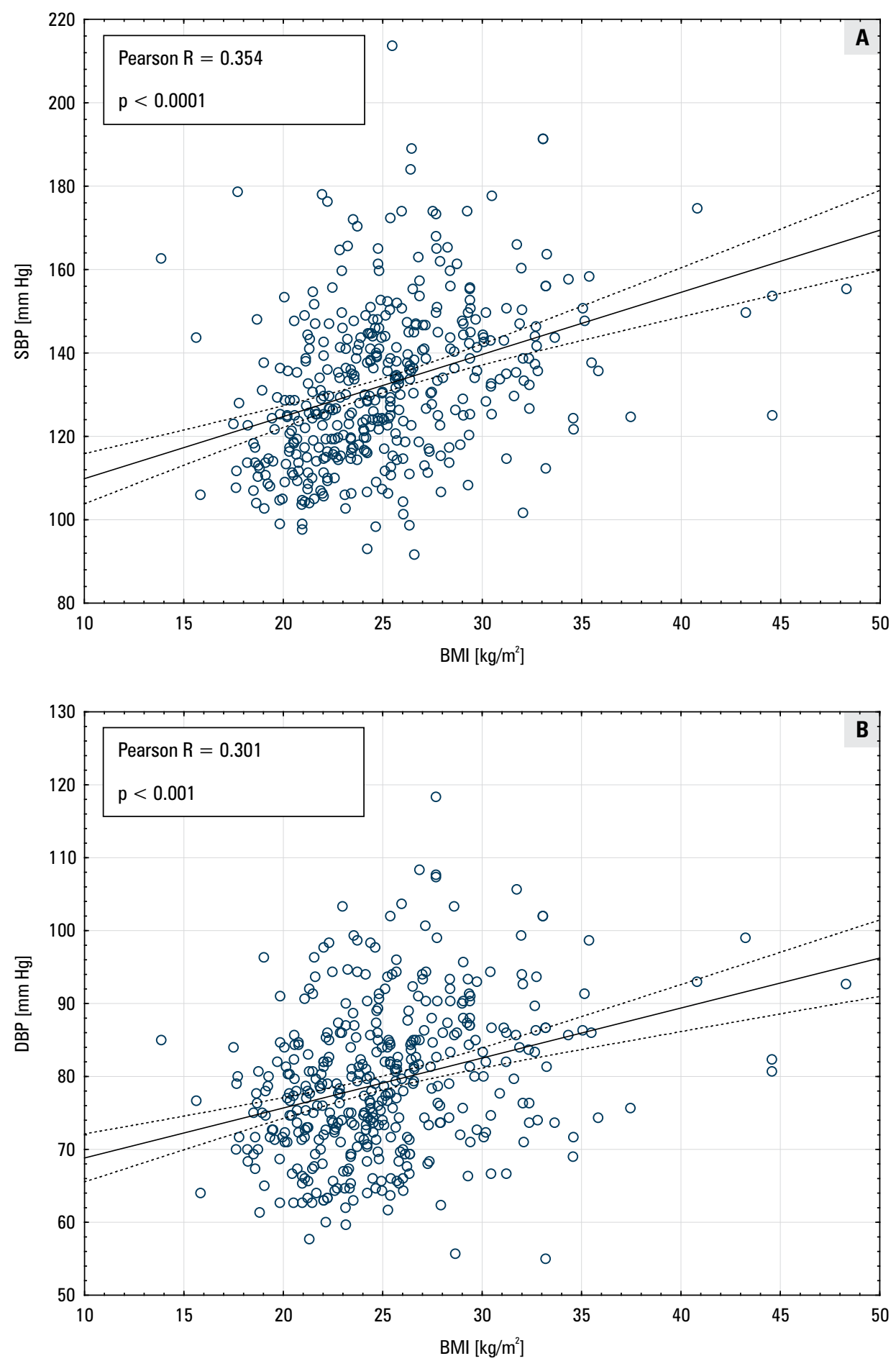

Figure 2. Correlation between mean systolic blood pressure (SBP) and BMI (A) and between mean diastolic blood pressure (DBP) and BMI (B)

DBP. Differences between HR measurements were statistically significant only between the first and the third reading.

To evaluate factors determining SBP differences between consecutive measurements, multiple regression analysis was performed. The regression model included age, first SBP reading, sex, BMI, antihypertensive drug use, alcohol consumption, cigarette smoking and diabetes. In our analysis only age $(b=0.088 ; p=0.006)$, first SBP value $(b=-0.267 ; \mathrm{p}<0.0001)$ and $\operatorname{sex}(\mathrm{b}=2.90588$; $\mathrm{p}=0.006)$ remained in the model, significantly determining BP decline in consecutive measurements (Table II). The first SBP value was the strongest 

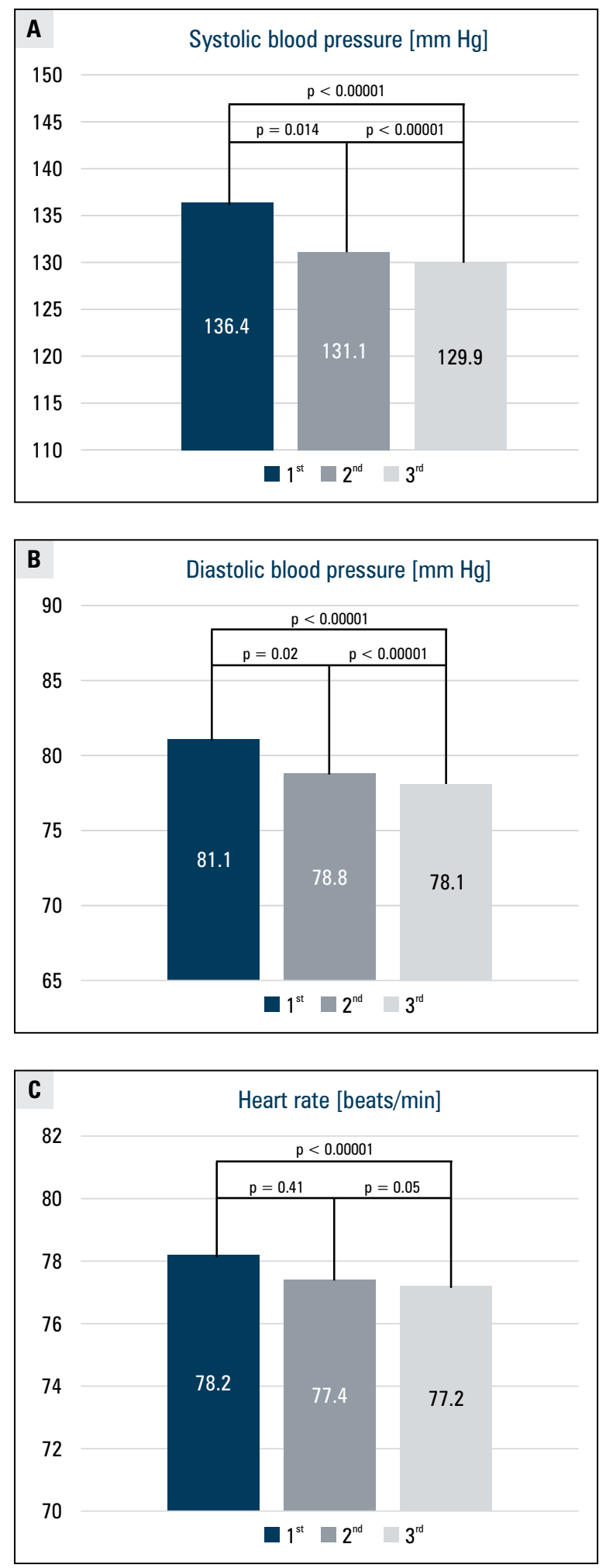

Figure 3. A. Systolic blood pressure (SBP); B. Diastolic blood pressure (DBP); C. Heart rate (HR). Differences between consecutive measurements

predictor of $\mathrm{BP}$ variability. BP declines were greater in younger participants, those with higher first SBP value and in women.
Table II. Factors determining SBP decline between consecutive measurements - results of the multiple regression analysis. Regression coefficient $R=0.44$. Adjusted $R^{2}=0.19$

\begin{tabular}{|l|c|c|c|}
\hline & b & SE & p-value \\
\hline Age & 0.09 & 0.03 & $<0.01$ \\
\hline Female sex & 2.91 & 1.06 & $<0.01$ \\
\hline First SBP & -0.27 & 0.03 & $<0.001$ \\
\hline BMI & 0.19 & 0.12 & 0.10 \\
\hline $\begin{array}{l}\text { Antihyperten- } \\
\text { sive drugs }\end{array}$ & 2.56 & 1.31 & 0.05 \\
\hline $\begin{array}{l}\text { Alcohol con- } \\
\text { sumption }\end{array}$ & 1.17 & 0.69 & 0.09 \\
\hline $\begin{array}{l}\text { Cigarettes } \\
\text { smoking }\end{array}$ & 0.05 & 1.49 & 0.97 \\
\hline Diabetes & -0.03 & 2.14 & 0.99 \\
\hline
\end{tabular}

SBP — systolic blood pressure; BMI — body mass index; $b$ - regression coefficient; $S E$ - standard error

Elevated BP (SBP $\geq 140 \mathrm{~mm} \mathrm{Hg}$ and/or DBP $\geq 90$ $\mathrm{mm} \mathrm{Hg}$ ) among all volunteers was detected in 188 subjects (44.9\%) when the diagnosis was based on the first reading, in $148(35.3 \%)$ when using the mean value of three measurements, in $156(37.2 \%)$ - using the mean value of the first and the second reading and in $138(32.9 \%)$ - using the mean value of the second and the third reading. Moreover, among volunteers without previous history of $\mathrm{AH}$ elevated $\mathrm{BP}$ was detected in 119 participants (diagnosis based on the first $\mathrm{BP}$ reading), in 88 subjects (based on the average of three measurements), in 92 (based on average of the first and second reading) and in 79 (based on average of the second and third reading).

\section{Discussion}

Our analysis showed that, in consecutive measurements, BP is characterized by high degree of variability with noticeable decline from the first to the last reading. The phenomenon of BP changes in several measurements was already documented in the literature; however, its determining factors are not well understood.

Our observations are in line with data by Wietlisbach et al. who reported that the average value of BP in the second reading was lower than in the first one by $3.2 \mathrm{~mm} \mathrm{Hg}$ for SBP and $1.1 \mathrm{~mm} \mathrm{Hg}$ for DBP [7]. Mo et al. reported even higher differences in SBP and DBP between the first and third reading (10 $\mathrm{mm} \mathrm{Hg}$ for SBP and $3 \mathrm{~mm} \mathrm{Hg}$ for DBP) [8]. In other studies, differences in consecutive BP readings were also described, but they were significant only for SBP $[10,11]$. 
BP variability in our analysis was strongly determined by the first SBP value. Similar results come from the data by Schulze et al. [6]. In his study, SBP and DBP levels were the strongest predictors of BP decline between consecutive measurements explaining $13-14 \%$ of SBP- and $8-9 \%$ of DBPdifferences [6].

In our analysis BP declines were greater in women compared with men. In the literature, data about the sex influence on BP variability are disparate. In the study by Schulze et al., SBP declines were comparable for men and women, but DBP declines were more pronounced in women [6]. The phenomenon of white coat effect, sharing the same pathophysiological mechanism as BP variability in consecutive BP measurements, has known higher prevalence in women than in men, what is in line with our observation [12]. On the other hand, slightly higher DBP declines in men compared to women were reported by Loo et al. [9] while Wietlisbach et al. did not observe changes in the extent of BP reduction between sexes [7].

Our analysis showed significant relationship between age and BP variability. We noticed that younger participants had greater BP changes between consecutive measurements. In contrary, Schulze et al. showed that BP variability increases with age [6] while Wietlisbach et al. did not observe differences in BP decline between subjects from different age groups [7]. The higher BP variability in elderly was detected in the Finn-Home study [13]. Interesting data come from the study by Veloudi et al., in which interaction between baseline $\mathrm{BP}$ value and age were the strongest predictors of BP changes. The interaction between age and the first SBP level resulted in younger individuals with higher SBP having greater changes from the first reading to the second one, than older individuals with comparable SBP [14]. Modesti et al. showed that differences in BP values obtained during two separate home visits were more significant in younger $(<30$ years $)$ than older participants [15].

These findings underline the need for the special attention which must be paid to the number of BP measurements in diagnostic evaluation, particularly in young individuals.

In our study the number of BP readings had the impact on the potential diagnosis of arterial hypertension. This problem was highlighted by several other studies. Schulze et al. also showed that the BP decline leads to different estimates of elevated BP if they are based on different readings or their combinations. In this study the first measurement resulted into $9 \pm 11 \%$-points higher prevalence estimates of hypertension/borderline hypertension compared to the second or third reading. The combination of the second and the third reading provided the lowest prevalence estimates, like in our analysis. Moreover, the analysis of data obtained in the National Health and Nutrition Examination Surveys 1999-2008 showed also the impact of the number of BP measurement on BP classification [16].

These results create a ground for discussion about home blood pressure measurements (HBPM) and 24hour ambulatory blood pressure monitoring (ABPM) which seems to be necessary to assess actual $\mathrm{BP}$ values. $\mathrm{HBPM}$ is an effective option for management of $\mathrm{AH}$ and may eliminate an alerting reaction which occurs in a clinical environment. It is also a better predictor of cardiovascular outcomes compared to standard office BP measurements [17]. Another valuable tool in daytime as well as night time $\mathrm{BP}$ readings and assessing BP changes is ABPM [18]. The 2018 ESH/ ESC guidelines for the management of $\mathrm{AH}$ recommend the use of out-of-office BP measurements as an alternative strategy to repeated office BP measurements to confirm the diagnosis of hypertension and underline that these tools can also provide important additional clinical information [4]. 24-hour BP variability presents a positive relationship with organ damage [19] and cardiovascular morbidity. Not only 24-hour BP variability is connected with clinical implications but also variability during subsequent $B P$ measurements. In the Dallas Heart Study a transient BP elevation during first measurement (known as an alerting reaction) was independently associated with renal injury, increased left ventricular hypertrophy and adverse cardiovascular events [20].

Current guidelines underline that parameters of BP variability may provide useful and additional information in some circumstances and are valuable tools for research [4].

Hypertension being usually asymptomatic condition and having high prevalence needs to be actively screened for. Following current guidelines, screening programmes should be established to ensure that $\mathrm{BP}$ is measured in all adults at least every 5 years and more frequently in people with a high-normal $\mathrm{BP}$. When hypertension is suspected because of an elevated screening BP, the diagnosis should be confirmed either by repeated office BP measurements over a number of visits or by out-of-office BP measurement using 24-hour ABPM or HBPM.

\section{Conclusions}

Correct measurement and interpretation of the $\mathrm{BP}$ is essential in the diagnosis and management of $\mathrm{AH}$. 
Multiple BP reading should be routinely performed in the process of BP evaluation even in screening actions and initiatives. The combination of the $2^{\text {nd }}$ and $3^{\text {rd }}$ measurements seems to be superior to single reading. When hypertension is suspected because of an elevated screening BP, the diagnosis should be confirmed either by repeated office BP measurements over a number of visits or by out-of-office BP measurement using 24-hour ABPM or HBPM.

$\mathrm{BP}$ variability is strongly determined by baseline SBP value, sex and age.

\section{References}

1. Lopez AD, Mathers CD, Ezzati M, et al. Global and regional burden of disease and risk factors, 2001: systematic analysis of population health data. Lancet. 2006; 367(9524): 1747-1757, doi: 10.1016/ S0140-6736(06)68770-9, indexed in Pubmed: 16731270.

2. Lewington S, Clarke R, Qizilbash N, et al. Prospective Studies Collaboration. Age-specific relevance of usual blood pressure to vascular mortality: a meta-analysis of individual data for one million adults in 61 prospective studies. Lancet. 2002; 360(9349): 1903-1913, indexed in Pubmed: 12493255.

3. Zdrojewski T, Rutkowski M, Bandosz P. Ocena rozpowszechnienia i kontroli czynników ryzyka chorób serca i naczyń w Polsce: Badania NATPOL 1997, 2002, 2011. In: Kopeć G, Jankowski P, Pająk A. ed. Epidemiologia i prewencja chorób układu krążenia. Medycyna Praktyczna, Kraków 2015: 57-64.

4. Williams B, Mancia G, Spiering W, et al. 2018 ESC/ESH Guidelines for the management of arterial hypertension. Eur Heart J. 2018; 39(33): 3021-3104, doi: 10.1093/eurheartj/ehy339, indexed in Pubmed: 30165516.

5. Mancia G, Bertinieri G, Grassi G, et al. Effects of blood-pressure measurement by the doctor on patient's blood pressure and heart rate. Lancet. 1983; 2(8352): 695-698, indexed in Pubmed: 6136837.

6. Schulze MB, Kroke A, Bergmann MM, et al. Differences of blood pressure estimates between consecutive measurements on one occasion: implications for inter-study comparability of epidemiologic studies. Eur J Epidemiol. 2000; 16(10): 891-898, indexed in Pubmed: 11338119 .

7. Wietlisbach V, Rickenbach M, Burnand B, et al. Combining repeated blood pressure measurements to obtain prevalences of high blood pressure. Acta Med Scand Suppl. 1988; 728: 165-168, indexed in Pubmed: 3202026.

8. Mo R, Lund-Johansen P, Omvik P. [How much is the decrease in blood pressure shown by repeated measurements during the same examination?]. Tidsskr Nor Laegeforen. 1993; 113(2): 214-217, indexed in Pubmed: 8430404.

9. van Loo JM, Peer PG, Thien TA. Twenty-five minutes between blood pressure readings: the influence on prevalence rates of isolated systolic hypertension. J Hypertens. 1986; 4(5): 631-635, indexed in Pubmed: 3794336.

10. Jamieson MJ, Webster J, Philips S, et al. The measurement of blood pressure: sitting or supine, once or twice? J Hypertens. 1990; 8(7): 635-640, indexed in Pubmed: 2168453.

11. Burstyn P, O'Donovan B, Charlton I. Blood pressure variability: the effects of repeated measurement. Postgrad Med J. 1981; 57(670): 488-491, indexed in Pubmed: 7301696.

12. Tocci G, Presta V, Figliuzzi I, et al. Prevalence and clinical outcomes of white-coat and masked hypertension: Analysis of a large ambulatory blood pressure database. J Clin Hypertens (Greenwich). 2018; 20(2): 297-305, doi: 10.1111/jch.13181, indexed in Pubmed: 29370477.

13. Johansson JK, Niiranen TJ, Puukka PJ, et al. Factors affecting the variability of home-measured blood pressure and heart rate: the Finnhome study. J Hypertens. 2010; 28(9): 1836-1845, doi: 10.1097/ HJH.0b013e32833b6c8a, indexed in Pubmed: 20508528.

14. Veloudi P, Blizzard CL, Srikanth VK, et al. Age-dependent changes in blood pressure over consecutive office measurements: impact on hypertension diagnosis and implications for international guidelines. J Hypertens. 2017; 35(4): 753-760, doi: 10.1097/ HJH.0000000000001227, indexed in Pubmed: 28253219.

15. Modesti PA, Rapi S, Bamoshmoosh M, et al. Impact of one or two visits strategy on hypertension burden estimation in HYDY, a population-based cross-sectional study: implications for healthcare resource allocation decision making. BMJ Open. 2012; 2(4), doi: $10.1136 /$ bmjopen-2012-001062, indexed in Pubmed: 22874627.

16. Handler J, Zhao Y, Egan BM. Impact of the number of blood pressure measurements on blood pressure classification in US adults: NHANES 1999-2008. J Clin Hypertens (Greenwich). 2012; 14(11): 751-759, doi: $10.1111 /$ jch.12009, indexed in Pubmed: 23126346

17. Mallick S, Kanthety R, Rahman M. Home blood pressure monitoring in clinical practice: a review. Am J Med. 2009; 122(9): 803-810, doi: 10.1016/j.amjmed.2009.02.028, indexed in Pubmed: 19699371.

18. Drawz PE, Abdalla M, Rahman M. Blood pressure measurement: clinic, home, ambulatory, and beyond. Am J Kidney Dis. 2012; 60(3): 449-462, doi: 10.1053/j.ajkd.2012.01.026, indexed in Pubmed: 22521624.

19. Frattola A, Parati G, Cuspidi C, et al. Prognostic value of 24-hour blood pressure variability. J Hypertens. 1993; 11(10): 1133-1137, indexed in Pubmed: 8258679.

20. Velasco A, Ayers C, Das SR, et al. Target organ complications and prognostic significance of alerting reaction: analysis from the Dallas Heart Study. J Hypertens. 2016; 34(2): 226-234, doi: 10.1097/ HJH.0000000000000774, indexed in Pubmed: 26485459. 